REVISTA ANDALUZA DE ANTROPOLOGÍA.

NÚMERO 3: MIGRACIONES EN LA GLOBALIZACIÓN.

SEPTIEMBRE DE 2012

ISSN 2174-6796

[pp. 148-182]

http://dx.doi.org/10.12795/RAA.2012.i03.08

Fecha de recepción: 09/01/2012

Fecha de aceptación: 10/05/2012

\title{
OTRAS MIGRACIONES: LOS LATIN KINGS EN ESPAÑA EN EL RELATO DE F.
}

\author{
MAURO CERBINO ${ }^{*}$ ) Y ANA RODRÍGUEZ $\left(^{* *}\right)$ \\ $\left.{ }^{\star}\right)$ Flacso Sede - Ecuador \\ ${ }^{* *}$ Fundación Museos de la ciudad de Quito
}

\section{Resumen.}

Este trabajo propone una discusión en torno a algunos de los problemas relacionados con la migración juvenil a España mostrándolos a través de la mirada y la experiencia vivida por F, un miembro ecuatoriano de la organización denominada los Latin Kings. Se analizarán las inadecuadas condiciones del destino que hacen posible la razón de ser y reproducción de esta organización, intentando mostrar de qué modo F, en un hábil y variado juego de adaptaciones, reinvenciones y traducciones de sus existencias en Ecuador y en España logra mantenerse y reproducirse socialmente en situaciones hostiles. A través del relato de vida de este joven ecuatoriano se logra mostrar la conflictividad y la incorporación de una subalternidad como el signo biopolítico del racismo y la discriminación.

Palabras clave: Migración, Latin Kings, Jóvenes, España, Organización juvenil, Discriminación. 


\begin{abstract}
.
The following research proposes a discussion about the difficulties related with youth migration to Spain, through the eyes and the experience of F, an Ecuadorian member of the organization known as the Latin Kings. It will analyze the inadequate conditions of destiny, that makes possible the meaning of being and the way of reproduction of this organization, trying to show how $\mathrm{F}$, in a diverse and skilled set of adaptations, translations and reinventions of his existence in Ecuador and Spain manages a way to maintain and socially reproduce in hostile situations. Through the life story of this young Ecuadorian, it is possible to reveal the conflicts and the incorporation of a bio-political sign of racism and discrimination in a subaltern organization.
\end{abstract}

Keywords: Migration, Latin Kings, Youth, Spain, Youth organization, Discrimination.

\title{
1. INTRODUCCIÓN
}

Ligados a los flujos migratorios desde Ecuador a España que se intensifican notablemente a partir de final de la década de los 90, debido a razones directa o indirectamente relacionadas con las múltiples crisis económicas que el país experimenta en aquellos años, muchos adolescentes y jóvenes emprenden ese mismo camino. La mayoría de ellos lo hacen bajo la dinámica de la reagrupación familiar que en España se empezó desde el primero de agosto de 2003, fecha de introducción del obligo de visado para nacionales ecuatorianos al espacio Shengen. Antes de la imposición del visado se hablaba de una reagrupación "de facto" en los términos de lo que podríamos definir como un conjunto de estrategias que las familias ponían en marcha para reunirse en los lugares de destino. Sin embargo hay otros jóvenes, como es el caso de F. - cuyo relato de su experiencia en España viene a continuación - que deciden salir del país por razones distintas a las de la reagrupación familiar, dado que sus motivos son de índole personal y muestran una faceta poco contemplada en los estudios de migración. De todos modos, para aquellos casos de reagrupación familiar, es importante notar que según estudios realizados (Feixa et. al. 2006) ${ }^{1}$, la mayoría de los adolescentes que emigran a España lo hacen en contra de su voluntad y sin tener un proyecto personal que les permita medir las ventajas de vivir en un nuevo país, lo cual los exponen a múltiples dificultades y su adaptación no es exenta de complicaciones (Suárez-Orozco, 2000). De ahí que esos jóvenes experimentan varias rupturas relacionadas con el hecho migratorio. En primer lugar cuando no participan en la decisión que su madre, su padre o ambos toman de salir del país para buscar nueva vida en el exterior. Es una decisión que solo padecen porque no han sido consultados y que llega repentina sin muchas posibilidades de "procesamiento oportuno" (Martín et al., 2012). En algunos casos logran atenuar esta ruptura porque quedan al cuidado de los

1. Para tener una visión general basada en un número significativo de entrevistas a jóvenes “latinos”. 
abuelos o de algún otro familiar cercano; en otros experimentan una fuerte sensación de abandono que podría conducirlos a buscar protección en organizaciones pandilleriles u otras formas de supervivencia (Kim, 2004).

La segunda ruptura se refiere al momento en el que, una vez más, por decisión unilateral de sus padres, el joven deja el hogar que compartía con los abuelos, el entorno familiar amplio, el barrio de los amigos y conocidos, el colegio o el trabajo, para reagruparse con sus progenitores, esos que a menudo son denominados como los familiares de "ahî".

La tercera ruptura es la que se produce por un triple desencuentro. El primero es con sus padres en el lugar de destino, porque los semblantes que tenían de ellos ya no son los mismos que obtienen una vez reunidos. El número de años trascurridos desde la separación ha contribuido a generar una transformación tan profunda que de modo recíproco produce una sensación de extrañeza en ambos. Situación que puede agravarse si, tratándose del reencuentro con la madre, ésta ha optado por tener una nueva pareja con una persona no ecuatoriana. Muchos testimonios dan cuenta de la tensión que se crea entre el joven y el nuevo miembro de la familia por ser "diferente" e "irreconocible". El segundo desencuentro se produce a raíz de las distancias, en ocasiones muy notables, que los jóvenes experimentan entre la imagen de bonanza y de buena vida que se habían construido del país donde viven sus padres (imagen que se sostiene fundamentalmente en las remesas que recibían), y el impacto con una realidad de sacrificio, de limitaciones que sus padres les trasmiten una vez en el país de destino. Muchos jóvenes descubren así y a su pesar una realidad muy distinta a la que se habían imaginado, lo que contribuye a sostener un rechazo a la actitud sumisa que perciben tienen sus progenitores en relación al empleo que han conseguido o a las manifestaciones de desprecio que la sociedad en general utiliza hacia ellos, llegando a no compartir su comportamiento o incluso a sentirse avergonzados por ellos.

El tercer desencuentro es más amplio y es de carácter social, puesto que los jóvenes, al contrario de los adultos que voluntariamente deciden emigrar, aterrizan en el país de destino sin tener una red a la que hacer referencia para sortear los primeros momentos que normalmente se caracterizan por ser los de mayor complicación. Este elemento de ruptura es tal vez el más significativo, si se tiene en cuenta que en el mejor de los casos la calidad de acogida en la familia y la constitución de un ambiente afectivo se ven fuertemente limitados por los extenuantes horarios de trabajo de los progenitores, quienes ante esto recurren a la escuela como un escenario posible para atenuar el golpe del viaje y del cambio radical. De las entrevistas, sale claramente expresado este afán de los padres de los jóvenes recién llegados, de asegurarles un puesto en un colegio como primera y a veces única medida de su integración a la nueva realidad. Sin embargo, una vez en el colegio, los jóvenes migrantes experimentan dificultades que ahondan la sensación de desorientación en lugar de atenuarla (Delpino, 2007). En primer lugar por 
ser catapultados de una realidad educativa a otra muy distinta, y a lo que se agrega, en el caso de escuelas o colegios catalanes el problema de tener que hablar en otro idioma, si se tiene en cuenta que este problema es considerado a menudo una pretexto para que los educadores subrayen los "déficits" de los nuevos alumnos, lo que muestra de paso la impreparación del sistema educativo español para tratar con estudiantes extranjeros.

Es en un contexto de esta naturaleza aquí brevemente resumido, agraviado por la existencia de un panorama social, político y policial adverso a los jóvenes migrantes y al que éstos deben enfrentarse una vez en España, donde se pueden ubicar algunas de las razones que hacen viable la reactivación de una organización juvenil llamada la nación de los Latin Kings (en adelante LK) en España de la cual F. es un integrante. A continuación se relatará los comienzos de las actividades de la organización y la historia de F. quien se apoyo en ella a su pesar por no tener alternativas de reproducción social viables en un territorio hostil.

\section{LK EN ESPAÑA}

Según varios testimonios recogidos en el trabajo de campo efectuado en Madrid, Barcelona, Valencia y Murcia, la nación LK tiene su acto de fundación en España en febrero del 2000 en Galapagar, un pueblo de las cercanías de Madrid. Son King Eric, con la chapa de King Wolverine y King Baby Black los que dan los primeros pasos de la organización a la que les dan el nombre de Sagrada Tribu América Spain (STAS). Está claro que la nueva organización quiere distinguirse de la versión ecuatoriana (STAE) de la Nación, proyectarse como una organización autónoma, a pesar de la proveniencia ecuatoriana y de la afiliación a STAE de sus miembros.

Es necesario resaltar este aspecto porque es uno de los cuestionamientos que al interior de la Nación se han producido hasta la actualidad: si se debía o no mantener vínculos formales con la organización ecuatoriana por el hecho de que la enorme mayoría de los miembros de la organización en España son ecuatorianos y porque una parte importante son reyes ecuatorianos. Las posiciones se han dividido al respecto y se pueden resumir así.

De un lado, hay quienes creen que la nación LK en España, no obstante se deba mantener con una única constitución ${ }^{2}$ (2) que fija una concepción unitaria, tiene que construir un rumbo independiente de la organización ecuatoriana porque los problemas y las oportunidades en España configuran un contexto disímil al ecuatoriano. Cuando hemos preguntado por los inconvenientes o las dificultades que viven los ecuatorianos en España las respuestas han sido:

2. La constitución LK es el conjunto de textos escritos a lo largo del tiempo de existencia de la organización, lo que representa la base de estabilidad de la misma porque la dota por decirlo de algún modo de un horizonte de significados compartidos por sus miembros. En otras palabras la constitución LK vendría a ser una especie de "acta fundacional" de la organización, lo que sin embargo no excluye las modificaciones que se han dado en el transcurso del tiempo (ver Brotherton D.; Barrios L.; 2004). 
(King J.): Hay muchos problemas, primeramente, que aquí no ha habido, no hay mucha nación (se refiere a la nación LK), lo he vivido en carne propia en muchos sentidos, por ejemplo cuando recién llegamos a vivir a Valladolid, la gente te quedaba viendo un poco mal, te sentías extraño, a la hora de ir a un lugar público te quedan viendo mal, o te dicen no, no. Una vez cuando yo viajaba de Madrid acá, me dijeron de una forma despectiva que no sabía leer, porque yo -nuevo aquí en España, nuevo- no sabía bien cómo va este tema de los trenes, todo eso y yo preguntando ahí en la ventanilla, y me dicen: "Ah, supuestamente los colombianos no saben hablar bien español, pero usted es analfabeto”, me dice, “¿De dónde eres?”, me dice, bueno algo así me dijeron. Yo me cabreé, no sabía si insultarle o que decirle. Mejor, me dejo confundido, tuve que ir a preguntar a una persona, a uno que estaba ahí esperando, y él me explico cual es el que va. No todos son así, eso sí, como en todo lado, hay gente buena, mala, pero en gran mayoría si hay gente que es muy racista aquí en España.

¿Entonces, digamos, hay un porqué de la refundación de la nación, en España?

(King J.): Sí, sí, porque también hay mucha gente que mira como nosotros, ¿me entiendes?, estamos solos aquí, necesitamos, bien o mal, el apoyo de alguien más que sea para conversar, para compartir los problemas, los únicos que tenemos son los hermanitos, que incluso estando mal económicamente a veces, han organizado canastos, han ido a dejar cosas a mi casa, ¿me entiendes?, por muchas cosas más, para compartir, hacer unidad, hacer nación.

Por otro lado, hay quienes reivindican el hecho de que la nación de Ecuador se ha vuelto, en relación a otros territorios poblados por miembros ecuatorianos de la organización, como una especie de nueva "madre tierra", sin perjuicio del reconocimiento incuestionable otorgado a la ciudad de Chicago como la única propiamente dicha ${ }^{3}$. Los que sostienen esta tesis dicen que solo reconociendo la filiación con la nación de Ecuador, toda la organización se puede mantener unida más allá de la distancia que hay entre los diferentes capítulos, y que al revés, la fundación de un capítulo autónomo sólo español, pone en peligro esa unidad de la que se necesita para cumplir con las funciones primordiales de la nación, como son la protección y las oportunidades de progreso para sus miembros. Las divisiones producidas por estas distintas perspectivas se han ido ahondando con el pasar del tiempo, y han determinado una profunda fragmentación al interior de la nación no exenta de tensiones y conflictos muy profundos.

De todos modos, el capítulo español de la nación fue adquiriendo una dimensión

3. La Nación de los Latin Kings se funda en Chicago (EEUU) en la década de los 40 del siglo pasado; esto le confiere a esta ciudad el apelativo de "madre tierra puesto que desde ahí la nación se propaga primero a otras ciudades de los EEUU y luego a comienzos de los años 90 a Ecuador, en particular a Quito y Guayaquil. 
internacional por haber dado cabida a miembros que no sólo no han sido exclusivamente ecuatorianos -siendo jóvenes de otras nacionalidades "latinas" - sino también permitiendo la entrada a jóvenes "autóctonos", especialmente mujeres". De hecho, la primera reina coronada ${ }^{5}$ por la organización en suelo español ha sido una joven española residente en Galapagar, que como hemos dicho es el lugar de nacimiento de la nación LK en España. Maverick, que es el apodo de esta joven, así cuenta su experiencia en la organización, mostrando los motivos por los qué decidió formar parte de ella, sus aportes a la nación y también algunos de los conflictos que allí ha vivido y el desenlace con su salida.

Del diario de campo:

Encontramos a Maverick en Galapagar una tarde de abril de 2007. En un momento muy difícil de su vida porque pasaba por líos judiciales debidos a su pertenencia a la nación LK que, incluso, la llevaron a transcurrir unos meses recluida en una cárcel -"en el pabellón de aislamiento junto con etarras porque me consideraban alarma social", narra. Ella, que con sus 18 años había participado de la organización desde el primer momento de su fundación, atraída por un grupo de jóvenes latinos "guapos" con estética rapera que se mostraba diferente y "más a puesto" de aquellos "raperillos españoles que no me agradaban".

"A mí siempre me gustaron mucho los morenos, además es una cosa que se percibe siempre también no, entonces fue un poco la mezcla, la gente diferente, a mí nunca me ha gustado la gente de mi pueblo y todo eso que hay no, entonces el ambiente aquí era un poco podridazo. Yo también me vestía como rapera, pero muy sola como un cubo rarito, en el instituto me decían ¿por qué te vistes así? y esa música que tu oías pues para encontrar un $\mathrm{CD}$ te tenias que patear medio Madrid y encima pagar unos precios desorbitados y luego yo pasar a la discoteca y no te gusta la música que ponen en la discoteca y todo así no se, empiezas a oírla así un poquito, mira mi amiga, mi amiga la chica que estaba saliendo con Eric [se trata de Eric Velastegui] ella es de Bélgica y en Bélgica sí que hay mas cultura funky y con ella empecé a escuchar, pues yo a ella la conocí con 14 años y con ella empecé a escuchar poco mas esa música yo antes me vestía rapera pero no tenia cultura musical así, pero luego con ella empecé a aprender.

4. Lo mismo se ha dado en otros casos en los que la nación ha incorporado miembros no "latinos", como en Italia (ver Queirolo et al. 2007). Es interesante notar que la nación LK en estos países funciona como un signo que no solamente se nutre de "lo latino" como en el caso estadunidense, sino que trasciende esta condición etnogenética y atrae también a jóvenes españoles o italianos, convirtiéndose así en una especie de metonimia de toda condición de "desplazamiento" o marginación social que viven los jóvenes en general incluyendo la escasa existencia de espacios adecuados para la reproducción social, el ocio o la recreación; más adelante retomamos este asunto.

5. Los miembros de la organización se "coronan" "reyes" o "reinas" luego un periodo de prueba y de observación pasando por algunos estadios y el nivel de rey o reina es el más alto en la organización. 
Para que Maverick pudiese estar con la nación tuvo que romper con su madre e ir a vivir con Eric, quien, por su parte, la mantenía dado que sus ingresos eran escasos. La vida en la casa de Eric fue lo que mejor recuerdo le ha dejado, porque sentirse parte de la organización significó para ella dar un sentido nuevo e importante a su vida monótona que transcurría en el pueblito. Nunca se sintió una extraña, además porque rápidamente asumió la forma de hablar de los sudamericanos, un aspecto significativo y relevante que le facilitó la integración y limaba asperezas que pudieran presentarse con los otros (y otras) integrantes. En los dos años transcurridos en la casa de Eric, Maverick realizo la traducción del inglés al español de una buena parte de la literatura LK (proveniente de los EEUU) de la que disponía Eric. Esta actividad le mereció un amplio reconocimiento en la organización. Sin embargo Maverick pasó momentos de crisis profunda que ella atribuye a la relación con Eric que a veces se hacía conflictiva. Es importante resaltar que uno de los señalamientos que hace cuando habla de Eric es la reproducción de una actitud racista (o tal vez despectiva) hacia los españoles. Un actitud racista que como se ha visto es denunciada por muchos ecuatorianos que viven en España. Maverick se da cuenta casi en seguida que uno de los principales motivos de la existencia de la nación en España -el racismo hacia los sudamericanos- es lo que al mismo tiempo ésta reproduce en su acción cotidiana.

En muchos fragmentos de la entrevista asoma claramente que para una joven como Maverick la nación representaba un espacio novedoso de socialización, de diversión y al mismo tiempo de sentido de altruismo y de solidaridad con "lo latino" discriminado y objeto de racismo. También se da cuenta de los fuertes límites que la nación pone: la existencia de una presión, aunque no abiertamente obligación, de tener que cumplir órdenes, de actuar de modo mecánico sin pensar mucho en qué se hace, Además Maverick, quien se enrola en la nación más o menos por juego, observa y no tolera las flagrantes contradicciones que los miembros de la organización protagonizan en cuanto a que, por un lado, las reglas escritas prescriben ciertas normas de conducta y, por el otro, estas mismas normas se infringen fácilmente. Con todo, lo que mayormente no tolera Maverick es el machismo imperante en la nación, y a la vez el comportamiento dócil y pasivo que tienen las jóvenes mujeres en relación a este trato de los hombres. Esta constatación le producía asfixia y empezaba a percibir que la nación era un espacio demasiado cerrado que no dejaba que sus miembros convivieran con el resto de la sociedad.

\section{¿Que ideas te hiciste cuando leíste la literatura LK?}

"Que (las reglas) eran muy sectarias, demasiado comprometidas, no sé como se dice en otro sitio pero aquí es que eran muy "flipao" y otras estaban muy bien. Hay gente como Eric, que piensa que no hay nada más allá de la nación, y otra mucha gente con la que estoy más de acuerdo que dice que la nación son propósitos u 
objetivos, pero nada tiene que regir tu vida, está tu familia, están tus padres, la sociedad, tu vida personal y todo eso tienes que valorarlo exactamente igual, yo con ellos estoy mucho más de acuerdo obviamente, hay partes que no te gustan, hay partes machistas que no te gustan, y que quieres cambiar, y hay que hacer algo para cambiarlas".

Maverick ya no pertenece a la nación, ha tenido que afrontar un juicio planteado por la Audiencia Provincial de Madrid por el delito de "asociación ilícita" junto con su compañero, también ex miembro de la organización. Sin embargo en los momentos libres sigue apoyando a algunas "reinas" en asuntos relacionados con problemas de discriminación de género que puedan vivir al interior de la nación.

La experiencia de Maverick retrata de modo significativo el papel con el cumple la organización LKmás allá de su anclajea la realidad ecuatoriana, la capacidad de proyectarse como una organización transnacional no obstante el fundamento racial de "lo latino" o tal vez precisamente por la utilización performática de este significante, de las derivas de la "raza" como señala Queirolo (2009) a su vez definidas en términos de "Atlántico latino" (parafraseando a Gilroy, 2003) para indicar un "conjunto de oportunidades y de prácticas del transnacionalismo juvenil y generacional" (2009: 129). En este sentido lo "latino" más que una condición de etnogénesis funciona como un espacio de construcción juvenil de prácticas -por ejemplo de estilos musicales- que siendo globalizados puede atraer, y de hecho atraen, a otros sujetos juveniles no latinos.

Interesa ahora mostrar cómo se reorganiza y estructura la nación LK en tierras españolas por medio de las experiencias que un rey vive una vez que decide emigrar a ese país. En la reconstrucción del relato de vida de $\mathrm{F}$, un joven quiteño de 25 años que se ve obligado a emigrar por una situación conflictiva que se le presenta en su país de origen, es posible dar cuenta de aquellos procesos migratorios de des y relocalización que dan sentido a la transnacionalización de la nación LK. Es haciendo referencia a una etnografía global y multi-situada (Marcus 2001) que permita observar las conexiones y los intercambios entre lugares distintos y sin embargo unidos por dispositivos de comunicación como es el Internet, por los viajes y las idas y vueltas imaginadas o concretas, que se puede ir registrando la dimensión transnacional de una organización como la de los Latin Kings.

\section{RELATO DE VIDA DE “F”, UN REY LATINO EN ESPAÑA (IDA Y VUELTA)}

En el mundo en que viajo estoy incesantemente creándome.

Y es yendo más allá de las hipótesis históricas e instrumentales que iniciaré mi ciclo de libertad (Frantz Fanon, Piel Negra, Máscaras Blancas) 


\subsection{Entrada}

El viaje de F abre varias temáticas que delinean el universo de registros en los que esta vida se desarrolla, mostrando al proceso migratorio como un develador de subjetividades, de la relación con la marginalidad, con la exclusión y con las formas de organizatividad juvenil.

Las condiciones sociales de marginalidad y exclusión de las que muchos jóvenes pretenden salir al migrar, se vuelven a encontrar de un modo algo similar en países de destino como España, ante lo cual la organización de los Latin Kings funge como un ámbito que permite la reproducción social de la vida de muchos de estos jóvenes, lo que se da especialmente para quienes - cuando salen del país por reagrupación familiar -, en contra de su misma voluntad inicial de integrarse a la sociedad española (Delpino, 2007; Feixa et. al., 2006; CIIMU, Informe 2005).

Cuando F tenía 17 años perdió a su madre. En el mismo año encontró a la nación LK, organización de la que hace parte desde hace 14 años. En el 2003 emigró a España de donde fue deportado 4 años más tarde a Ecuador. En base a conversaciones que he tenido con él durante este tiempo decidimos contar esta historia que es un fragmento de la vida de F mirado desde acá (Ecuador), en un tiempo que es el de hoy en el que su liderazgo dentro de la organización tiene más sentido que nunca, y en que -precisamente por la misma razón- nos es imposible dar cuenta de una serie de detalles que lo expondrían demasiado. Sin embargo, vale la pena anotar que $\mathrm{F}$ ha participado en la revisión de esta escritura -antes, durante y después- de su redacción, corrigiendo datos pero sobretodo "expresiones" y "tonos", en busca de una pertinencia del texto con sus huellas autobiográficas.

Las perspectivas teóricas, que permiten elaborar un sentido en torno a esta relato de vida, abordan tres ejes problemáticos: el rol de la imaginación en la subjetividad migratoria; la reproducción -en países de origen y en países receptores- de condiciones translocales de marginalidad y exclusión; los procesos de empoderamiento y la lucha por el reconocimiento de la nación LK (u organización) como acción colectiva y "sentido de vida" de una subjetividad migrante.

\section{2. "No hay como mi tierra" [Rememorando la infancia, la adolescencia y la vida en Ecuador: condiciones de marginalidad y exclusión que se reproducen en España]}

Los relatos que presentamos a continuación son posteriores a la experiencia migratoria y resultan testimonios muy diversos, fruto de un ejercicio de memoria que se encuentra ya atravesado de una serie de valoraciones incorporadas en el proceso de integración a la sociedad española. Tal vez lo único que todos estos testimonios tienen en común es precisamente que pueden dar cuenta de dos aspectos al mismo tiempo: la reproducción de condiciones de marginalidad (los suburbios de las ciudades españolas resultan 
tan excluyentes y de lazos sociales tan precarios como los suburbios de las ciudades ecuatorianas), y la situación de exclusión social de los jóvenes (en un caso debido a condiciones socioeconómicas -en Ecuador- y en otro caso debido más a condiciones de etnoestratificación y racialización -en España-). Esta analítica comparativa permite por un lado apuntalar "la crítica del nacionalismo metodológico" que es posible a partir de la definición del concepto de transnacionalismo, un concepto "que intenta superar la visión etnocéntrica de la experiencia migratoria, es decir la invisibilización del país de origen y las conexiones y relaciones que los migrantes mantienen con dicho origen" (Herrera, 2008: 73), en función de pensar en las condiciones transnacionales de marginalidad y exclusión; que los barrios no aptos para la vida se reproducen por razones materiales y simbólicas tanto en Ecuador como en España.

La infancia de F no le pedía favor a ninguna historia ideal. Una familia "muy unida", muchos tíos y familiares cercanos, alegrías y problemas se alternaron pero en su recuerdo "lo básico siempre estuvo: calor y cariño", que nunca le faltaron, ni preocupación de sus padres, ni lo más mínimo en términos materiales. Sin embargo la nación LK resultó ser un referente fundamental en el momento de una pérdida importante, la muerte de su madre.

Yo siempre fui diferente, hice lo que quise, no malo, pero siempre fui, digamos, curioso. Cuando les vi por primera vez a los muchachos ahí parando por donde yo vivía yo me dije: quiero ser como ellos. Fue después de lo de mi mami. Era hace un montón de años y aquí sigo con altos y bajos, pero a la nación le debo que en un momento duro de mi vida ellos fueron lo único que me importaba.

La vida de F en Ecuador, antes de sospechar siquiera que se iría a España, se repartía entre el trabajo como asistente de contaduría en un colegio católico, como padre de familia de dos niños, como esposo, y como rey en la nación. Había sido difícil sentar cabeza después del duro golpe que significó la muerte de su madre, pero había contado siempre con el apoyo de su padre y de su abuela, un apoyo no solamente material, a pesar de las dificultades económicas que tenían, sino afectivo, una enorme confianza y un cariño que “pocas veces tienen la mayoría de los niños y los jóvenes". Hasta el día de hoy, más de 10 años después de la muerte de su madre, después de haberse casado, emigrado y regresado - "deportado, humillado y sin un centavo en el bolsillo"-, cada noche su abuela lo espera con un plato caliente y conversa con él. También lo apoyan su hermano mayor y su tío, ambos confían en que F trabaja por "el bien de otros jóvenes de manera desinteresada" como afirma su tía. La presencia de la abuela ha sido muy importante porque le ha permitido tener un hogar, un referente, un sentido de pertenencia en la vida cotidiana. La abuela sabe que los viernes se va a "hacer zona" (el control del territorio) con los hermanitos y llega tarde, sabe que los domingos pasa una parte del día con ellos y el resto con la familia. La abuela parece entender la entrega de $\mathrm{F}$ a la nación como una misión cristiana o como una militancia: 
esto es como lo más importante de la vida de mijo (mí hijo), yo le he dicho que ya deje y se dedique a algo de provecho, a algún trabajo, pero él sigue ahí creyendo, entonces yo también creo. A pesar de todo, lo que él hace lo hace por los demás y eso es siempre bueno, es como algunos hacen política y otros catecismo.

La vida se complicó para $\mathrm{F}$ en ese tiempo de juventud antes de irse a España. Había sido un buen momento para él y para la nación, pero esos buenos momentos se veían alterados, desestabilizados por situaciones imprevistas, por "pitos" (líos) inesperados. F sentía una presión muy fuerte relacionada con las lógicas internas de la arquitectura organizativa en constante cambio. Problemas y amenazas empezaron a crecer y la ida a España se transformó en una opción para apartarse de la organización y para no seguir temiendo por su vida.

Dentro de la misma organización de los Latin Kings hemos escuchado historias muy diferentes en cuanto a sus contenidos, tonos e intensidades. Si F tuvo todo el apoyo de su familia durante su infancia y su adolescencia y a pesar de haber tenido condiciones materiales de escasez, esa misma suerte no les tocó a muchos otros jóvenes emigrantes ecuatorianos en España, entre ellos algunos reyes que encontramos y entrevistamos allá. Contar con "el apoyo de la familia" quiere decir que ésta está volcada hacia el bienestar de los menores, de los hijos, debido a que los padres han logrado establecer un acuerdo de participación compartida con las responsabilidades ${ }^{6}$.

Sin embargo de que muchas de las historias de los jóvenes que emigran a España se parecen a la de F, o sea que no se trata necesariamente de experiencias de descomposición social más graves que las que podemos encontrar en territorios españoles u europeos en general, los medios de comunicación españoles se empecinan en atribuir una supuesta "maldad" de los jóvenes latinos a la precariedad social y económica que padecen en los países de origen. En general se menciona el origen para naturalizar la precariedad, la violencia o la agresividad, para poder extraer luego una relación naturalizante entre origen y crimen. Este discurso estigmatizante de la mayoría de la prensa, los jóvenes ya lo conocen también desde Ecuador. La diferencia es que en España se trata nuevamente de un doble estigma: joven y latino. Edad y "raza". Autoridades y a veces también investigadores tienden a repetir el discurso de los medios, funcionales a las políticas de derecha, sin

6. Durante la experiencia de intervención del Proyecto Centro Tecnológico de Organizaciones juveniles CETOJ-Turubamba (barrio del sur de Quito, en el que se plasma un proceso de acompañamiento para la transformación de la nación LK en Ecuador) hemos podido anotar que en el caso de aproximadamente el 10\% de los adolescentes o jóvenes participantes, se da una situación familiar favorable, a pesar de las condiciones materiales de pobreza. Los jóvenes que cuentan con la confianza de sus padres también disponen del "permiso" y el apoyo de éstos para las actividades de la nación, sean estas culturales, sociales o de formación/capacitación. 
medir las implicaciones atroces que estos discursos conlleva ${ }^{7}$ (7). La reproducción de la marginalidad también depende de este círculo narrativo que tiene valor de verdad.

En Reyes Latinos, libro escrito por periodistas españoles en tono amarillista, se puede leer la historia del joven "Rodrigo" contado en estos términos.

Había llegado de Ecuador con doce años y tuvo que esperar año y medio hasta que tuvo su primer amigo. En su barrio de Guayaquil la vida era dura. Los chicos de su banda y él se drogaban con pegamento y cuando estaban puestos, se hacían cortes en el brazo con el cuchillo para demostrar su hombría. Se peleaban mucho, siempre con otros barrios. Pero en Barcelona fue peor (Botello y Moya, 2005: 88-89).

Si bien se puede entender que una de las problemáticas centrales de la emigración latinoamericana a España es la de la precariedad de los lazos sociales en los países de origen, no podemos reducir las causas de la exclusión social que sufren los emigrantes ecuatorianos en España a esa "precaria" condición social de la que provienen. Si bien hay una importante relación entre el déficit simbólico ${ }^{8}$ y la dificultad de inclusión, también hay una relación entre el diferencial que surge entre los sistemas valorativos de lo social entre culturas ecuatorianas y culturas españolas. Nos referimos a que, si bien los servicios públicos (garantizados por el Estado como educación y salud) se han desarrollado ampliamente en países como España con respecto a América Latina, no podemos decir que esta es una verdad suficiente para determinar el triunfo de un modelo sobre otro.

El desarrollo de los servicios públicos especialmente en lo concerniente a educación puede ser valorado positivamente en términos estadísticos y de número de beneficiarios, sin embargo en cuanto a participación e integración de las poblaciones minoritarias (españolas como extranjeras) el sistema aparece como cuestionable, con la única excepción representada por el sector de la salud. El dispositivo pedagógico estatal que opera en la escuela no permite directamente la puesta en marcha de mecanismos de inclusión efectivos. Tomemos en cuenta el testimonio de una psicóloga chilena que vive en Barcelona, madre de un joven LK a quien nos referiremos también más adelante ${ }^{9}$ (9):

7. A modo de ejemplo de ver el artículo de opinión, alarmista y perversamente nacionalista, "La excepcionalidad española" que publica El País, escrito por David Reher y Blanca Sánchez Alonso, profesores investigadores. Disponible en: http://www.elpais.com/articulo/opinion/excepcionalidad/ espanola/elpepuopi/20090218elpepiopi_13/Tes.

8. Con déficit simbólico nos referimos a que hay un reducido bagaje de referentes culturales y sociales que permitan hacer frente a los agresivos procesos de imaginarización estigmatizante de los que son víctimas los jóvenes latinos en España.

9. Jefa de familia, psicóloga, que llega a Barcelona queriendo realizar un postgrado en peritaje psicológico penal forense, a través de contactos proporcionados por colegas chilenos. Durante el primer año, trabaja de mesera entre 6 pm y 3 am, lapso de tiempo durante el cual el hijo mayor (14) cuida a la hija menor (4). 
...es un poco complicado, porque yo creo que acá los colegios reciben muchos chicos inmigrantes no sólo de Latinoamérica, pero tampoco hay un programa efectivo de integración [...] Te voy a citar una frase del tutor de X, que no es el profesor jefe sino es el encargado de acompañarlo, me dice un día, 'bueno mira yo no sé, hay un chico que viene de Bolivia, de Ecuador, no sé son todos iguales', es el comentario de él, y 'no se integra, él está siempre en una esquina, no habla con los otros chicos, tiene dos, tres amigos y yo no entiendo porqué, bueno yo sé que la emigración es difícil, pero nunca tanto', palabras de él. Bueno no sé qué cara habré puesto, pero no podía entender cómo un profesor, tutor de estos chicos, es capaz de decir bueno la emigración es difícil pero nunca tanto... Bueno cuando yo le digo a $\mathrm{X}$, qué pasa con el chico de Bolivia, el dice no mamá él no es de Bolivia es de República Dominicana y yo me quedo ah... es un poco eso, cuando el profesor tutor le es igual, es Latinoamérica, da igual Perú, Bolivia, son todos negritos igual, esa cosa se refleja también la integración que tienen los chicos en el colegio.

No es sólo el hecho de que esos dispositivos hayan fracasado -no obstante el trabajo que realizan los trabajadores sociales o los educadores de calle- lo que da cuenta de la complejidad de la exclusión social, sino más bien la postura asumida por la prensa amarillista que da a consumir noticias estereotipadas sobre la base de la racialización de los migrantes. También en los espacios del trabajo y de la socialización existen condiciones que reproducen ese mismo estereotipo, por medio del cual, se exponen a los migrantes como "diferentes culturalmente". Así, se asiste a la articulación de un potente discurso que termina por imaginarizar los migrantes reduciéndolos a una "pura diferencia cultural", o a "pobres trabajadores", o en algunas casos hasta a "potenciales delincuentes", todo esto no obstante la presencia de dispositivos pedagógicos del estado español o incluso precisamente por ellos que intentan mediar.

En Ecuador, la pobreza se caracteriza por producir problemas sociales inatendidos, aún cuando afecte a una mayoría de la población. En España en cambio la pobreza es considerada un problema social que afecta a una minoría poblacional, pero sin embargo su imagen produce consumos mediáticos desaforados. La prensa rosa española no deja de explotar la pobreza y la violencia doméstica (así como no deja de adular a los personajes de la farándula local y global). Las imágenes que explotan la relación entre "raza" y pobreza está presente en los dos escenarios -ecuatoriano y español-, aunque diversamente connotados: "En Ecuador nos estigmatizan por ser pobres más que por ser oscuros... en España aunque te vuelvas muy rico no te van a dejar de ver como a una especie de indio". A tales condiciones de precariedad simbólica, la acogida efectiva a los inmigrantes resulta casi inoperable, casi tan inoperable como es en Ecuador el intento de las autoridades especialmente policiales de desconfiguración de bandas y organizaciones de la calle que como se sabe garantizan orden y protección. Así, la reproducción de marginalidad se 
debe en España a la exclusión y a la racialización de las prácticas culturales; y en Ecuador, a la ausencia de oportunos dispositivos pedagógicos y programas estatales que permitan garantías mínimas sobre lo público (espacio, vivienda, educación, salud, etc.).

A esto se debe sumar que los jóvenes ecuatorianos no cuentan en España con la valoración de la familia como una estructura fundamental del vínculo social, como lo es en Ecuador. La familia, la comunidad o el barrio son conceptos ejes de la articulación de la relación social en América Latina que en España tienen menos importancia que el derecho o la ley en general, cuando a los inmigrantes se refiere. En términos de políticas de reagrupación familiar, las familias transnacionales afrontan una serie de limitaciones en cuanto a la realidad que se vive en Ecuador, en donde la existencia de hijastros o de familia ampliada es una situación muy común que la ley española no contempla (Herrera, 2008: 82). La configuración abierta de la familia presencial se ve desconocida por las leyes y políticas de inserción que promueven la reagrupación familiar cerrada, es decir que asume que las familias transnacionales son nucleares cuando en realidad muchas de ellas son ampliadas o monoparentales, y en muchos casos tienen a la madre a cargo de los trámites y los gastos ${ }^{10}$.

F nos cuenta cómo, al llegar a España, una de las cosas que más le sorprende de la vida cotidiana de la gente en los barrios, es que los territorios no son de la comunidad, es decir no se negocian con la gente que vive allí, sino como un supuesto derecho de todos, que abstrae las posibilidades reales de inserción en base a la negociación.

Los parques ahí no son de la gente de ahí, aunque acá en Ecuador también un parque o una cancha de fútbol sea del Municipio, tú si quieres usarlo tienes que hablar con la gente del barrio y ponerte de acuerdo aquí. Allá en cambio yo vi parques, como uno por allá por Cuatro Caminos, donde cada grupo usaba una esquina: los marroquíes por un lado, los negros africanos por otro, los gitanos por otro y los ecuatorianos por otro. Pero nunca hablábamos entre nosotros, cada quien en su esquina y punto...porque todos teníamos derecho. Pero los únicos que no tenían su esquina eran los españoles, esos ni querían vernos...

La idea de un derecho puramente abstracto, que no se "ejerce" sino que solo sirve para impedir a los ciudadanos de segunda, o sea a los inmigrantes, que se apropien lo que es "de todos", resulta en un derecho excluyente. Los inmigrantes están por fuera de la universalidad del derecho, es decir de la exigibilidad del derecho de igualdad. El derecho -universal- sirve para poner a funcionar operaciones de racialización -que niegan lo universal, haciendo caer su máscara- y ponen a funcionar valoraciones locales del otro, del inmigrante.

10. La mayoría de los jóvenes que conforman la organización de los Latin King en España ( $80 \%$ de los entrevistados) llegaron por proceso de reagrupación familiar y, en todos los casos, el reencuentro con la madre o el padre puede considerarse como dificultoso. 
Para entender mejor lo que sucede con estos espacios públicos, que son a la vez territorios de negociación y de la legitimidad, en donde el derecho y el urbanismo van en contra de lo urbano, Manuel Delgado ubica el foco de interés de los municipios en las prácticas de regeneración urbana, que son comunes a ciudades como Barcelona, Buenos Aires, Bogotá o Guayaquil, en donde el administrador municipal ha actuado como urbanista en contra de los urbanitas. Estas prácticas responden a intereses comerciales y de renta del suelo, producen desplazamientos de los habitantes autóctonos de los lugares regenerados por el aumento vertiginoso de la plusvalía del suelo, y convierten los lugares en parques de diversión para nacionales pero sobre todo para turistas extranjeros. En el caso de Barcelona, y también de Guayaquil, la regeneración se ha acompañado de ordenanzas de civismo, las que ponen en evidencia las intenciones de crear un ambiente aséptico en el que cultivar "las buenas costumbres" y al cual aplicar medidas de control de los ciudadanos. Quienes de este modo tienen que demostrar ser "aptos” para ocupar esos lugares. Delgado (2007) llama "políticas de cortesía” a estos planes municipales, los que reproponen modelos antiguos por los cuales los ciudadanos debían mostrar ser portadores de adecuados modales de actuación en el espacio público. Hoy estos modales convierten a las personas que transitan por los lugares regenerados en especies de "extras" -recalca Delgado- de personas que simplemente aparecen ahí, en un espacio vaciado de sentido antropológico de apropiación y depurado de toda conflictividad social. Lugares "bonitos" y "limpios" que pretenden ocultar la pobreza y convertirse en espacios "seguros" por la presencia masiva de policías (en España) o guardias privados (en Ecuador). En estos espacios más bien céntricos de las ciudades o en barrios de alta circulación, se prohíbe actuar con espontaneidad, hay que ir con "vestidos apropiados" y evitar suscitar sospechas, so pena de ser discriminado o sancionado. Los administradores municipales quieren vender la mentira de que la vida transcurre sólo en el "espacio público" (que en el fondo es privativo). Que la gente viva en viviendas absolutamente precarias y entornos cercanos no aptos para la vida no parecen ser sus prioridades. En los barrios precarios de las periferias o los suburbios, a menos que estos sean expropiados por especulaciones inmobiliarias transnacionales que unen intereses empresariales y municipales en general, los espacios públicos se negocian más allá de la participación de autoridades, en el performance cotidiano en el que los mecanismos pedagógicos del estado o del municipio (escuela, policía, etc.) dejan de ser efectivos y pasan a ser los mecanismos performativos de vecinos nacionalistas españoles que se enfrentan a los gestos performativos de los inmigrantes, generándose ahí una conflictividad antagónica.

Otros testimonios refuerzan esta idea cuando ponen en el tapete el problema de la censura al ruido y a la música. Sin necesidad de ser conducidos al tema, la mayoría de los jóvenes entrevistados dicen sentirse censurados por no poder escuchar la música latina a alto volumen, no poder ni reír, ni bailar, ni contar cachos. 
A los españoles no les gusta echar la música alta en la casa como hacemos nosotros... un buen reggaetón y llaman a la policía... dicen que no respetamos y te mandan al... pero ¿y ellos?, no respetan a nosotros como somos.

Seentiende así que las prácticas culturales de cada grupo producen nuevas territorialidades que reivindican el tipo de lazo social predominante en sus países de origen. Entre las formas más comunes de territorialización se encuentra la práctica de la moda, de la música y del baile. Estos elementos utilizados en la estereotipación de los jóvenes latinos en España, como sucede con toda relación de subalternización, es un proceso dinámico, ambiguo y ambivalente. Dinámico porque se configura en función de reglas de consumo cultural y musical que tienen que ver con un mercado global; ambiguo porque la misma música que detestan en sus vecinos latinos puede ser la que bailan en un espacio social reconocido para ellos; y ambivalente, porque aquellos signos que permiten reconocerlos y señalarlos con el dedo, son también los signos de una diferencia limítrofe con el otro español: aquello que los españoles usan para reconocerlos como diferentes es probablemente aquello que también los atrae. Así, el rechazo de lo latino parece competir con el deseo de lo latino (Hall, 1997; Bhabha, 2002; pássim).

Los jóvenes organizados no solo no se esconden o dejan de llevar su ropa a "lo ancho", sino que perseveran en utilizar este signo como una forma de identidad que exhiben, casi de modo provocador, tal como lo hacen en sus países de origen. Si juventud y "raza" son dos agentes de exclusión, para los jóvenes (organizados o no), acostumbrados a ser excluidos saben que su presencia en un parque es considerada sospechosa. En España esta condición se vuelve doblemente estigmatizante: no solo son mal vistos (y discriminados) por ser jóvenes (y vestirse de ancho por ejemplo), sino que también son discriminados por ser inmigrantes, lo cual aparece como una práctica normalizada de control.

El problema no es que nos paren y nos controlen los papeles mandándonos a la... que a ver tal por cual, qué donde vives, a punte grito... jaja... ya estamos acostumbrados... el problema es que siempre se quieren llevar por lo menos a uno...sino para que tanto operativo...

Desde el diario de campo, reportamos unas anotaciones sobre la actitud policial en relación a los jóvenes ecuatorianos miembros de los Latin Kings:

La reunión se realizaba en un barrio del sur de Madrid en Pan Bendito, uno de aquellos barrios a los que los taxistas no quieren entrar porque tienen la fama de ser altamente peligrosos. "Y sí que lo es", afirma el sacerdote de la parroquia, "pero no por la presencia de los jóvenes latinos, dado que aquí los problemas son otros, tienen que ver con la criminalidad organizada, pero esto a la policía no parece importarle". El lugar del encuentro es una sala de la iglesia parroquial, que como en muchas ciudades ecuatorianas, es el único espacio que acoge a estos jóvenes. Los 
actos previstos se desarrollan en un ambiente muy emotivo y alegre. Hasta que uno de los jóvenes que "custodia" la puerta entra alarmado a la sala y dice algo al oído de otro hermanito: afuera hay agentes de la 22, el tristemente famoso cuerpo especial de la policía. Si es así, saben que están ahí por ellos, porque están cometiendo el delito de reunión, ellos que son los miembros de una banda latina "peligrosa" que los jueces han declarado "asociación ilícita". Sí, como si de una organización del tipo ETA se tratara. Con el párroco salimos inmediatamente. Llegamos hasta la parada del metro, bajamos las escaleras, "es aquí donde normalmente los agarran, porque saben que por aquí deberán pasar necesariamente para regresar a sus casas, incluso tienen advertidos a los de la boletería a que soplen la presencia de grupos de jóvenes latinos que con sus atuendos tan particulares son fácil de reconocer" dice el sacerdote. No nos percatamos de nada, todo parecía despejado. Regresamos a la iglesia. Los chicos se tranquilizan y se retoma la reunión. Cuando termina, tomamos la decisión de salir en grupitos de tres personas, por no crear sospechas, por si acaso la 22 efectivamente esté al acecho. Es lo que acontece. Aparecidos de la nada, unos ocho agentes de civil y cinco autos de la policía hacen irrupción alrededor de la parada del metro. Piden los documentos de identificación. Les comunican que han recibido una llamada que denunciaba el robo de un celular y que están ahí por ello. El tono agresivo y los gestos displicentes los traiciona fácilmente. No hay duda de que el operativo había sido premeditado. Se cumple una vez más una cacería de bandas latinas. Nosotros, los investigadores, nos distribuimos en varias esquinas donde los jóvenes son detenidos, e intervenimos para ser testigos de la actuación policial y también para intentar convencerlos de que no hay delito alguno de por medio. Todos nos declaramos Latin Kings y que, si esto es un crimen, que se nos lleven a la comisaría. Es inútil, a la comisaría irá a parar un joven por no portar documentos, aunque constatemos que es su "portación de cara" lo que determina la momentánea detención. Junto a nosotros está un coronel de la policía nacional del Ecuador, en esos días ha tenido un papel extraordinario como acérrimo crítico de las autoridades locales. Ahora puede vivir en carne propia, estando en el lado contrario, el significado de un operativo policial al límite de lo legal y abiertamente xenófobo. Es una experiencia inolvidable que demuestra, si acaso era necesario, que lo que en Madrid hemos denunciado -el acoso policial a jóvenes latinos- no es una mera hipótesis sociológica.

Con el relato de vida se logra mostrar la conflictividad y la incorporación de una subalternidad que en términos estrictamente teóricos sería difícil de plantear, dado que en el recurso de las conversaciones superficiales sale el signo biopolítico: España me educa (dispositivo pedagógico del Estado-nación español) y (por lo tanto) a la vez me controla y me discrimina. La reacción a esta situación paradójica por parte del joven ecuatoriano resulta en una incorporación del signo mismo del español en su relación 
conflictiva con otro modelo para el que él resulta el subalterno. Los españoles introyectan el signo de la subalternidad presente en la idea de "milagro español" (el español es un milagro económico en la medida en que ha logrado recuperar su "atraso" en términos de desarrollo), y lo proyectan en su propia inmigración. El tercero de la relación de subalternización aparece siempre, produciendo una triangulación superpuesta. Ninguna de estas triangulaciones antecede a la otra, ya que resultan planos de un mismo diagrama. La marginalidad se reproduce en tanto las condiciones de inferiorización se reproducen de manera transnacional.

\subsection{Voy a tratar de decir por qué y cómo fue en ese viaje que me hice gente (...) [El viaje de Quito a Madrid o la constitución de una subjetividad migrante]}

F se fue de improviso, no tenía contactos previos en España, a pesar de que tenía alguna hermana de crianza o algún amigo de la organización por allá, nunca se puso en contacto con ellos, apenas se guardó un número de teléfono en el bolsillo, que le entregaron de última hora, perteneciente a un amigo de su hermano que sospechaban vivía en Madrid, "por si acaso".

Me fui porque tenía problemas aquí con la Nación, más que por motivos económicos ya que trabajaba y me iba bien. A pesar de esas cosas positivas, en Ecuador yo tenía otros líos y tuve que huir de los enemigos de la Nación, o sea de otros grupos.

F se fue en el mes de octubre (22 ó 27) del 2003, tenía 25 años. Se fue con el apoyo de su familia que estaba asustada a pesar de la poca información que él les había dado, tenía miedo de pensar lo que podría pasar si F se quedaba en Ecuador. No había posibilidad económica de pagar en efectivo a la agencia (a la empresa que fungía de coyotero), por lo que su abuelita prestó las escrituras de su casa para empeñarlas como garantía. "En parte uno, como persona que quiere salir de aquí, busca esas maneras... de que te financien, de poner algo en prenda... yo qué sé... de poner lo que sea con tal de salir del país". La idea inicial era "mandarlo" a Londres porque España ya era demasiado "berreado" y tenía miedo de caer en lo mismo en España, ya que la nación existía allí también, había sido fundada unos años antes por reyes que se habían ido a trabajar a España y había crecido por la concurrencia de hijos de emigrantes ecuatorianos y latinoamericanos.

El viaje de F se dio: averiguaron, la familia hizo los trámites de pago, los coyoteros de la agencia le dieron la bolsa y el pasaje para viajar. Sacó su pasaporte y se fue.

¿Qué pensaba cuándo me iba? Estaba asustado. Ir a un mundo nuevo solo, un mundo que imaginaba tan diferente. Estaba triste, de irme dejando a mi familia. 
Veía a todas esas personas en la malla del aeropuerto ${ }^{11}$ y me daba tristeza pensar que algunas de esas eran mi familia que se despedía de mí. Me iba dejando todo.

La agencia nos había explicado, a mí y a mi familia, que allá en Europa todo estaba arreglado.

Llegaría a Madrid, allí lo esperaría una persona que lo recibiría y lo embarcaría para Milano y después para Londres. Eso le aliviaba, que alguien lo esperaría en el aeropuerto y se haría cargo de él hasta que estuviera en su destino final. Llevaba consigo el dinero de la "bolsa" que debería entregarle a esa persona al llegar, después de mostrarlo en la ventanilla de migración a los controladores españoles. Esa persona lo embarcaría para el Reino Unido. "Todo está perfectamente planificado" le habían asegurado en la agencia. No era para menos: su padre había puesto sus ahorros y la abuelita había empeñado la casa para que ese viaje fuera posible. En Londres lo recibirían y le darían alojamiento los primeros días en un departamento donde viven otros emigrantes hasta que se ubicara en un trabajo. Para el trabajo, probablemente en albañilería o en servicios de limpieza o carga -que aparecía como algo difícil dado que F no hablaba inglés-, ellos mismos le harían el contacto. Así estaría sano y salvo, y con un nuevo futuro por delante y muy pronto podría empezar a enviar dinero para pagar la deuda con la agencia y empezar a ayudar a su familia.

Para ser su primer viaje en avión fue bastante largo, duró 18 horas y realizó dos escalas en Bogotá y Caracas, pero como tenía tantas cosas en qué pensar que lo empezaban a aturdir, mejor se dedicó a dormir, como para acostumbrarse a olvidarse de los problemas y de la preocupación que sentía. De allí hicieron escala en Milano, a donde pensó que volvería en pocos días de camino a Londres, allí le realizaron el primer control migratorio y le sellaron el pasaporte, tuvo miedo de tener algún problema en la aduana, se oían tantas historias de gente que le regresaban porque no tenía bien los papeles, pero no, él pasó sin problema. Hasta ahí todo iba en orden: "El susto empezó cuando salí en el aeropuerto de Barajas en Madrid, después de ver que nadie me esperaba".

Permaneció largo rato muy atento, mirando a todos lados, por más de una hora, y constató que nadie vendría a buscarlo. Entonces se empezó a asustar. No sabía qué hacer. Le habían entregado unos vouchers de un hotel que era donde le debía llevar el hombre que debía recibirlo, hasta embarcarlo para Milano y luego Londres. Pensó que debía dirigirse hacia ese hotel.

11. La "malla" es una parte del cerramiento que bordea la pista de los aviones en el aeropuerto de Quito, desde donde se puede verlos despegar, ya que no hay muro en esa parte sino simplemente una alta malla metálica. En los años 2000, cuando la emigración ecuatoriana se masificó, la "malla" se llenaba de gente que hacía su última despedida con la mano desde ahí: es gracias a la migración, además de otros factores, que los aeropuertos ecuatorianos de "no lugares" (Auge, M. 2000) se convierten en espacios antropológicos de la memoria. 
Buscó un teléfono, estaba muy nervioso. Tuvo que cambiar un poco de los euros de la "bolsa" para poder llamar por teléfono. Intentó llamar al celular del hombre que debía recogerlo pero estaba apagado. Espero una hora más y nada, seguía sin contestar. Entonces se decidió a llamar a $\mathrm{H}$, el amigo de su hermano $\mathrm{D}$, de quien había guardado el número en un bolsillo sin prestarle importancia, pensando que no necesitaría utilizarlo. $\mathrm{H}$ le contestó de inmediato, $\mathrm{F}$ se identificó y $\mathrm{H}$ se acordó de él enseguida. Le confirmó que vivía en Madrid. F le explicó la situación en la que estaba y H lo tranquilizó, le dijo que esperara allí y que él mismo lo iría a buscar una hora más tarde.

"Es algo tenaz, en país ajeno y solito ahí... al principio todo fue super duro. Mi papi, nos adora a nosotros. Él siempre ha sido bueno, incluso me mandó plata para que me regrese después de pocos días y no regresé. Al mes me quise regresar al estar durmiendo en un piso o un sillón y mal visto por la gente, que no puedes tener todo lo que te da la gana sino solo un lugar donde dormir”.

Hora y media esperó a H. Él en este primer encuentro le advirtió que nada era cómo los coyoteros lo pintaban en Ecuador, le propuso quedarse con él en vez del hotel. Pero F se quedó en el hotel del que tenía los vouchers. Intentó pasar los tres primeros días allí pero el lugar era una "porquería”. El hotel tenía las habitaciones con un urinario dentro del cuarto,: "Como me voy a quedar así? Qué me voy a quedar en un país, en un hotel sin conocer a nadie...entonces me fui a la casa del H".

Además, Hugo le explicó que la llegada a Londres no sería tan sencilla como tomarse un avión. Le comentó cómo funcionaba: debía darle su pasaporte al coyotero para que este le hiciera "viajar normalmente hasta Milano" y de ahí a Londres en avión. Pero había muchos que eran deportados desde Milano por no tener todos los documentos necesarios. F insistía en que todo se complicó el momento en que el coyotero no le esperó en el aeropuerto, si el hombre hubiese aparecido y lo hubiese llevado directamente a Milano para embarcarlo hacia Londres, F ni siquiera se habría enterado de las posibles complicaciones.

\subsection{Pero el destino es así}

De todas maneras se contactó con el coyotero porque debía entregarle la "bolsa" de dinero. H le había explicado que tenía que devolver ese dinero, sino sería muy grave en vista de todo lo que estaba en juego, incluyendo la casa de la abuelita. Se reunió con el hombre, este le explicó cómo se realizaría el viaje a Milano y luego a Londres.

Tenía pasaportes de muchos extranjeros y de entre ellos se debía escoger la firma que se pareciera más con la mía. Entonces le dije que me iba si él me firmaba garantías... que si es que a mí me regresaban de Milano, ni siquiera de Londres, [él y su familia] iban a seguir botando billete y para qué. 
El hombre, un ecuatoriano, argumentó que valía la pena intentar llegar a Londres ya que la situación era mejor a su parecer, porque en España ya existían muchos latinos y ecuatorianos para los mismos tipos de trabajos. Sin embargo, el coyotero le explicó que no existía garantía como las que F pedía, por lo que no se concretó el trato inicial.

Una cosa era una deuda de aproximadamente unos 1600 dólares a otra de 5000 dólares. Pero en cualquiera, no existían garantías: si los policías me agarraban la deuda quedaba. Si decidía irme a Inglaterra y me agarraban en la frontera me quedaba igual con una deuda de 5000, pero si me quedaba en España me quedaba con una deuda nada más de 1600 .

Lo pensó, lo consultó con sus familiares en Ecuador, quienes le dijeron que la decisión sería de él, a pesar de que hubieran querido que llegue hasta Inglaterra como lo había hecho un joven vecino de Turubamba, para que así se aleje definitivamente de los Latin Kings. Al siguiente día F le dijo al coyotero que no se iba para Inglaterra, porque no tenía ninguna garantía de que si no entraba, podía volver a intentar o le volvería a cobrar. De todas maneras y a pesar de las razones de F, después de poco tiempo, la agencia empezó a molestar a su familia en Ecuador, queriendo ejecutar las garantías de la casa de la abuelita, alegando que F no había cumplido con lo acordado.

F se fue con $\mathrm{H}$ a su casa. $\mathrm{H}$ vivía en una situación aún más precaria que la del hotel: era un departamento donde vivía mucha gente, algunos dormían en el piso, "solo faltaba que duerman encima de la mesa. A pesar de ello cuando el man me dijo: quieres quedarte? yo le dije: de una!"

$\mathrm{H}$ recién estaba uno o dos años en España, trabajaba como pintor, albañil o lo que surgiera. No tenía un trabajo estable. Le contó a F que él mismo cuando llegó a Europa intentó ir hasta Londres pero lo detuvieron en la frontera. Entonces se quedó en España, tuvo suerte de todas maneras porque a algunos los enviaban de vuelta sus países.

A través del relato de $\mathrm{F}$ es posible pensar que la subjetividad migrante se puede constituir a partir de una deseo de "salida" (huida) que no tiene que ver con un rechazo general de las condiciones de socialidad del país de origen sino con una amenaza puntual de violencia o de conflictos personales, que no es exclusiva de países como el Ecuador, que "fuerza" a la persona a empezar una vida lejos de esa amenaza ${ }^{12}$. Si bien la violencia tiene que ver con un círculo relacionado con condiciones estructurales, no podemos simplificar esta relación haciendo un silogismo permanente. La motivación para migrar no es siempre una "laboral", a pesar de que el horizonte predecible de la migración es el empleo. En

12. Para ilustrar esta afirmación podemos citar el hecho de que en Ecuador existen inmigrantes europeos (italianos, franceses y españoles) que se han instalado aquí porque tienen inconvenientes legales o situaciones de amenaza en sus países de origen. Asimismo podemos recordar que una parte de la Argentina y del Cono Sur de América Latina se pobló con victimarios europeos, prófugos de los juicios de la Segunda Guerra Mundial. 
este sentido es interesante anotar que el trabajo que hace la memoria en términos de estereotipos mediáticos es el de incorporar la idea en el sujeto migrante de que llegó para trabajar (de que se es un "migrante laboral") dado que el otro estereotipo, menos atractivo para el recién llegado, es el del migrante como delincuente o criminal (Cerbino, 2006). No existe una categoría generalizada que presente al migrante ilegal como un "exiliado" o como un "viajero" que encuentra en el trabajo una forma de sustento y de inserción social.

Estas últimas categorías implican el reconocimiento de una subjetividad que no corresponde a las necesidades de exclusión del país receptor, en este caso España. Europa, de modo general, necesita de "chivos expiatorios" en su carrera por la privatización de los servicios y la radicalización del discurso de la securitización. Así, según Stolcke (1994): "aunque es evidente que no se puede culpar a los inmigrantes del aumento del desempleo, de la escasez de vivienda, y de los deficientes servicios sociales, 'ellos' son los verdaderos chivos expiatorios de 'nuestros' problemas socio-económicos". En este sentido va también el análisis de Pedone (2001) en cuanto al papel de los medios de comunicación españoles en representar a la inmigración ecuatoriana como una amenaza para la sociedad; en efecto - señala en su trabajo- que uno de los adjetivos más usados para crear una imagen de esa inmigración por medio de narrativas periodísticas es la palabra "ilegal".

El proceso de subjetivación que permite el viaje a F como conciencia de su condición de sujeto soberano, le dota de la capacidad de decidir. "me di cuenta de que estaba por mi cuenta (las cursivas son nuestras), es decir de que tenía que decidir". El primer signo fuerte de esta subjetivación en el caso de $\mathrm{F}$ es la decisión de no tomar el riesgo de ir a Londres y quedarse en España. Aún cuando esta decisión pueda leerse como un mecanismo inconsciente de acercamiento a la nación LK representa la asunción de una voluntad frente a un recorrido preestablecido para los migrantes: respetar las redes y acuerdos con los coyoteros para garantizar el "éxito" de la migración laboral, en tanto dispositivo.

Por qué yo me iba a ir donde me dicen que me vaya... a los que se van del país por otras razones nadie les ve como criminales ni les dicen lo que tiene que hacer... Yo me fui porque tenía problemas en Ecuador, por qué no me iba a quedar en España?

Se puede resumir el conflicto que delinea las acciones subjetivas de $\mathrm{F}$ en su primer periodo en España como un conflicto con las etiquetas tradicionales del inmigrante: no sabe qué clase de migrante es, pero sabe perfectamente que clase de migrante no quiere ser. Su voluntad se define por la negación de algunas etiquetas, y está atravesada del duelo de la perdida. Esta negación configura un deseo de particularidad ("no quiero ser un migrante laboral más, pero tampoco quiero ser un delincuente, quiero ser una persona normal a la que nadie le mire mal"). 
El sufrimiento a veces te ayuda a ver mejor. Estando lejos me di cuenta de lo que vale lo que tengo aquí en Ecuador, es como que vi más claro. Irme me sirvió también para darme cuenta.

El viaje es entonces un proceso de concientización y de distanciamiento que permite a $\mathrm{F}$ un proceso de subjetivación que tiene momentos distintos, que pasa por la asunción de la pérdida. Finalmente, en el relato de $\mathrm{F}$ el viaje también es un proceso de autonomización con respecto a la condición que vivía en Ecuador como hombre miembro de una familia tradicionalmente machista.

Yo no sabía cocinar. Yo aprendí a hacer arroz en España. A cocinar no. De ahí todo eso era enlatados y enlatados y enlatados de arriba para abajo, pero la mujer de Gato me enseñaba vuelta a cocinar, me daba de comer. Aprende a cocinar, tienes que aprender me decía, aquí no te vas a pasar comiendo solo arroz con atún, arroz con albóndigas, no...

Aprendió a hacer cosas que en Ecuador habían sido rol de su mamá o su abuela, aprendió a limpiar, a cocinar y ser autónomo con las cosas de la casa. "Es que aquí [en Ecuador] más que machistas somos muy cómodos" nos dijo un día, "las mujeres en unos aspectos y los hombres en otros". Sin embargo en España

aprendí que era parte de ser alguien el ser autónomo", “creo que por eso tú me ves tan diferente a los otros, sobretodo en cómo yo les permito a las reinas que ellas mismas decidan lo que quieren hacer.

Este proceso le permite relativizar algunas reglas machistas de la organización por el contexto de autonomización del individuo y no tanto por el proceso de inclusión en la sociedad española entendida como una sociedad abierta e igualitaria en términos de género.

Yo aprendía a hacer todo y no se me cayeron las manos... pero igual aquí me gusta que mi abuelita se haga cargo de eso de la comida y todo. ${ }_{-} \mathrm{O}$ sea que te gustó es discurso de la igualdad de género?- o sea en algunas cosas, que las mujeres decidan, pero eso de que se anden emborrachando o se metan con uno y con otro, no tanto...o sea más claro que hombres y mujeres hagan los que les parezca pero con respeto.

La relativización de los gestos y quehaceres del hogar no conlleva una perspectiva de género tendiente a la revisión de los roles femeninos sino más bien un proceso de autonomización del varón con respecto de sus necesidades básicas. La autonomización es una parte del proceso de subjetivación en cuanto cuestiona la manera automática de vivir la relación asistencial de la mujer hacia el hombre y por ahí también, como una implicación, se cuestionaría los roles de género como algo dado o natural. 


\subsection{El viaje, pérdida y recuperación de la palabra}

Cuando uno viaja, reporta Chambers (1994), se desplaza de un punto a otro, y observa la nueva realidad del país en el que se encuentra momentáneamente con la perspectiva que le ha dado su país de origen, al que siente que pertenece. Cuando uno emigra la situación del sujeto es distinta, este se deshace parcialmente del capital cultural de origen en la medida en que necesita adaptarse a la nueva realidad, es decir que opera un cambio que le es demandado por la sociedad de acogida en función de una inserción en sus prácticas más básicas. La migración, a diferencia del viaje de ida y vuelta -dice Chambers-, es un viaje sin retorno. Las condiciones de origen son alteradas en cuanto el sujeto deja de ser el mismo. Se trata de que durante el viaje se ponga a funcionar la imaginación del sujeto viajante que reinventa su vida, su intimidad, sus redes y su función social.

En ese desplazamiento cultural se construye una subjetividad dispuesta a la traducción. Desde las formas y usos cotidianos del español hasta las prácticas y valoraciones culturales más conflictivas son sometidas a cuestionamientos por parte de sus propios representantes. Hay quienes en España afirman que existe una proximidad cultural que garantizaría una buena relación entre "autóctonos" y ciudadanos latinoamericanos. La realidad social no sólo no confirma esta afirmación, sino que se muestra contraria a ella, dado que esa supuesta proximidad se puede traducir en una trampa especialmente para personas de ciertas nacionalidades. La ecuatoriana es una de ellas; y existen estudios que demuestran la relación existente entre las necesidades estructurales del mercado del trabajo español de informalización y desprotección de los trabajadores con esa representación cultural de la proximidad que convierte a los latinoamericanos en "trabajadores preferidos" por los empleadores españoles precisamente por esas necesidades del mercado (Martín, Cuberos y Castellani, 2012). Además el hecho de que los ecuatorianos hablen el castellano, si bien podría significar tener una condición que facilita la comunicación y una mutua comprensión, se convierte en el imaginario dominante español en una descalificación toda vez que interviene la voluntad de comparar y establecer la existencia de una versión "apropiada" de esa lengua de la que los ecuatorianos no serían portadores. Desde esta óptica, ahí donde los ecuatorianos por medio del castellano intentan entender las situaciones novedosas que se les presentan en un país distinto al suyo, al mismo tiempo se hacen reconocibles por su "errónea" utilización. Lo cual los condena al desprecio público. Es inevitable que tengamos que reflexionar (luego de quinientos años) de qué modo vuelve a operar ese mecanismo que hace que la imposición de una lengua, además de violentar al sujeto en lo que más lo nombra y estructura que es su propio idioma, permite también reproducir una dominación basada en el establecimiento de un canon en el uso de ese idioma. Se puede afirmar que las marcas diferenciadoras gramaticales y fonéticas del "castellano ecuatoriano" cuya producción es posible gracias a que todo idioma funciona como un organismo vivo, y por ende cambiante y en permanente 
actualización, adquieren en España una connotación denigrante. Son innumerables los casos de maltrato a ecuatorianos por el sólo hecho de que su manera de hablar es asociada con la incapacidad de manejar situaciones que por el contrario dependen de la simple adquisición de hábitos, como por ejemplo la utilización del metro o del tren. En ciudades como Madrid los niveles de intolerancia y xenofobia alcanzados hacia los ecuatorianos, han propiciado el aparecimiento de varios nuevos "delitos": al de "portación de cara" se suma el de "portación de lengua" para ambos plasmarse en el "delito" de "portación de nacionalidad". Este último "delito" se registra por ejemplo en los aeropuertos españoles, cuando en el caso de ciudadanos ecuatorianos a los "normales controles" se agregan otros especiales, visiblemente indignos e infamantes. La configuración de todos estos y otros "delitos" tiene en la construcción social de estigmas el fundamento para una absurda "jurisprudencia” porque desconoce la primacía de la noción de ciudadanía sobre la de nacionalidad. En Madrid, muchísimos más testimonios dan cuenta de cómo en esta ciudad se han ido elaborando narrativas y pre-textos que han pretendido definir las características "peculiares” cuasi naturales de las identidades "proscritas”.

Algunas prácticas de construcción o reproducción de la identidad de origen -etnogénesis-, son abandonadas y otras se fortalecen a partir de las negociaciones que se establecen con la sociedad receptora. Según el testimonio de los jóvenes, el sujeto emigrante sufre de modo bastante evidente al menos dos procesos traumáticos de desubjetivación que pueden traducirse de modo sintomático: primero la pérdida abrupta de la familia y las redes sociales de origen, y luego, el encuentro también abrupto con la sociedad receptora que lo excluye y rechaza. En el caso de algunos jóvenes entrevistados, estos se refieren a la sociedad receptora en términos de un conflicto inicial representado por el "idioma": "a veces no me entendían al principio, me tocaba repetir o hablar más duro... eso mismo mira 'duro' es una palabra que nosotros utilizamos para decir "fuerte" en realidad". Este desfase idiomático surge en el momento de la llegada del emigrante, cuando comprueba que a pesar de hablar español este resulta ser una lengua extranjera, es decir que lo que tenía en mente como una ventaja resulta ser la huella de una relación colonial. La supervivencia colonial es la condición en las relaciones interpersonales de que sea el emigrante ecuatoriano el que debe hacer constantemente el esfuerzo de traducción y adaptación a la lengua española.

El problema no es el acento como dicen los españoles sino que no les da la gana de entender, quieren que se haga las cosas a su manera, la prueba es que los que son más frescos sí entienden y hasta les gusta cómo hablamos...

Siguiendo a Bhabha (2002) se puede decir que se trata de una lengua que es casi igual pero no completamente, no lo suficiente. Ese diferencial, ese residuo que separa el español madrileño del español quiteño resulta contener las marcas de la colonialidad, es decir de un universo simbólico de la pérdida. En la mayoría de los casos, los jóvenes evitan hablar en los primeros tiempos. 
En muchos casos el conflicto idiomático puede terminar en una pérdida momentánea de la palabra, es decir en una postergación crónica de la comunicación por temor al rechazo $\mathrm{o}$ al desconocimiento ${ }^{13}$. Esa pérdida de la palabra tiene que ver con varios otros aspectos de la precarización de la vida a la llegada: espacios de vivienda altamente reducidos, pérdida de la privacidad, búsqueda de trabajo o inmersión abrupta en el trabajo, separación de la familia sin tiempo de duelo. Este sentimiento de desarraigo puede ser tan fuerte que podríamos llamar a muchos de estos casos ya no experiencias migratorias sino experiencias de "trasplante" (Grinberg y Grinberg, 1984).

La palabra se recupera en este caso de modo paulatino, a medida que se encuentra ciertos momentos de estabilidad y se puede comenzar a establecer una red social con la que se intercambia experiencias e ideas, se sale, se bebe, se baila, etc. La palabra permite la reconfiguración de un mundo que parecía ya perdido, un mundo de lo conocido aunque no haya reconocimiento. La vergüenza que muchos ecuatorianos pueden sentir al hablar es algo que extrañó mucho a $\mathrm{F}$, aunque entendía por haberlo vivido en carne propia que al principio uno "como que se queda callado". Aunque se sintió intimidado en muchas situaciones iniciales, nunca dejó de hablar como ecuatoriano y aprendió a subir la voz y a "reírse de sí mismo y de los demás". Es que cuando "uno les oye gritar a esos manes [personas] también aprende a subir la voz". La palabra recuperada tiene que ver con la recuperación de un entorno de reconocimiento que no es la sociedad española ni el contexto laboral en general, sino la comunidad migrante co-nacional, o en el caso de los jóvenes Latin Kings, es la organización.

El testimonio de la psicóloga chilena citada anteriormente, cuyo hijo forma parte de la nación LK, explica así este proceso de su hijo de 14 años al llegar a España:

el primer año duro, duro, lo tuve en su habitación todo un verano (...), todo el tiempo en la habitación, quieres salir 'no', tienes amigos 'no', 'a mí no me gusta acá, con una idealización de Chile al máximo, empieza un proceso que empezara a valorar lo que se perdió y a valorarlo de una forma muy exagerada, también, partiendo de lo que son sus relaciones más cercanas que es su familia, que empieza a ser importantísimo estar con ellos, lo cual es normal, pero también empieza una idealización de su barrio, de sus amigos, de su colegio, todo lo que odiaba allá el colegio empezó a ser lo máximo. Y bueno como lo vimos como familia eso bastante, yo en lo personal bastante complicada porque en algún momento tenía miedo de salir de mi casa y de volver a mi casa y ver que mi hijo estaba colgado del balcón, yo me pasé un montón de veces, se me pasó esa idea de verdad.

13. Alex Schlenker, La Frontera Hablada, Investigación inédita realizada con el apoyo de una beca CEDIC, Quito, 2008. 
Yo sabía que él estaba entrando como a una especie de depresión, yo sé que él estaba bordeando una depresión de joven, que (...) son muy solapadas, muy duro para mí. Salía a trabajar de noche, y cuando llegaba a las tres de la mañana, era así como toc, toc, ¿estás?, 'sí.

La comunicación del joven se vuelve escasísima, en el colegio no habla con nadie, se comunica apenas con la madre. Hasta que encuentra la nación LK. Esta no solo le provee de reconocimiento sino de herramientas para enfrentarse a la exclusión, y además le permite operar una sutura con el pasado roquero de la madre y con la militancia de izquierda de su familia en Chile. La grupalidad garantiza una red social típicamente juvenil (consumos culturales: moda, música, baile, etc.) y un sentido de lucha y de protección en su situación de inmigrante. Parte de los motivos por los cuales los jóvenes ecuatorianos, latinoamericanos, de Europa del este, de África y de Asia se agrupan en comunidad, se transforman en las banderas de lucha y los contenidos de los objetivos de la organización: las problemáticas de "racismo", de exigibilidad de derechos, de exclusióninclusión educativa y laboral, de uso de espacios públicos, de reducción de las prácticas violentas en recurso de prácticas lúdicas y de diversión.

\subsection{Frente a la exclusión, surge la acción colectiva y la conciencia de conjunto}

El primer trabajo de F fue en una discoteca, como "cristalero", que consiguió por medio de unos amigos, amigos de hermanitos con los que se había encontrado. Ellos le presentaron a unas amigas, E una española y $\mathrm{M}$ una ecuatoriana. "Vacilaron" con ellas la noche que se conocieron, él y su amigo JC, y al día siguiente E le propuso el trabajo para limpiar cristales, aspirar y mantener los garajes. Se quedaron "de largo" trabajando a pesar de que les pagaban poco. Por otro lado, trabajaba los fines de semana de portero para un profesor, que daba clases y $\mathrm{F}$ abría la puerta a los estudiantes. Así su primer año transcurrió arreglándoselas con muchos trabajos irregulares. La inestabilidad no le permitía enviar mucho dinero a Ecuador aunque algo enviaba.

Era lo primero el empezar a vivir eso... porque tenías que saber donde vivir para que sea más barato, tenías que de ley comprarte el abono del mes porque esa es la base que te mantiene todo el mes para transportarte a todo lado. Si empiezas a comprar por 'ticketadas' de diez de un 'pique' y todo eso... es fatal.

En Madrid estuvo un tiempo trabajando en una empresa de limpieza de edificios, en sus recuerdos este periodo es evocado siempre de modo positivo. Describe el trabajo como empleado de esta empresa, no a sueldo pero con convocado con regularidad -de lunes a viernes y a veces hasta el domingo-, como una "experiencia maravillosa". Conoció a mucha gente de otros países, con quienes se relacionó en los espacios de trabajo. También conoció "a gente de España, quienes sabian lo que era, o sea un Latin King, y se sentían atraídos". 
Había marroquíes, había colombianos, había uruguayos, había de todo, y también había problemas. Es como que al conocer a esas personas descubrí que había gente de otros países que pasaba por cosas parecidas a nosotros los ecuatorianos (...)

Casi sin darme cuenta empecé a parar la gente. Creo que me dio ganas de hacer de nuevo algo con la gente [de la nación].

Algunos de esos trabajadores extranjeros en su misma circunstancia tenían familias, esposas,

se veía porque les mandaban la comida en las viandas..., nosotros los ecuatorianos también llevábamos bastantes veces nuestras viandas de arroz...los españoles se iban al bar, full bocadillo.

Empezó entonces a "parar gente" (juntar gente) pero sin querer, sin una intención precisa, no sentía que era lo mismo, no sentía que era su ambiente, y no quería empezar algo. En ese tiempo supo de EC, el máximo líder de la nación LK en España, pero se mantuvo distanciado.

"Parar gente" resulta una imagen interesante: quiere decir poner a la gente de pie. Aunque "parar" se usa en Ecuador para referirse también a simplemente "estar" en un determinado sitio o lugar de reunión. Cuando los muchachos dicen "nosotros paramos en Turubamba" se refieren a que el barrio de Turubamba es en donde suelen estar. Se puede constatar en sus usos que ese estar representa un encuentro con otros, un estar juntos y estar de pie, literalmente "parados afuera en la esquina". Parar es ocupar un territorio para hacerlo temporalmente "propio". Parar es entonces organizar a la gente ya que parar siempre se hace en grupo, en conjunto. Para territorializar hay que tener un acuerdo previo, aunque sea mínimo, el de "caminar juntos por una calle de una ciudad que nos es hostil, que no nos quiere". Ese acuerdo mínimo genera un territorio que es el de nuestro caminar. Territorializar es tomar los elementos que da la tierra para poder transformarla en territorio (Deleuze, 1991). La tierra no es entendida en términos naturales sino como espacio de la vida social. Territorializar, movimiento que sucede al mismo tiempo que desterritorializar y reterritorializar, quiere decir cambiar las relaciones de poder existentes entre determinados grupos sociales en un determinado espacio social.

A la pregunta ¿Que es una organización? F responde: es caminar juntos. Podemos entonces articular algunos conceptos o planos de conciencia que se superponen en este diagrama descriptivo de la organización en un contexto de inmigración marginal: exclusión / territorialización / acción colectiva / organización. Según Tilly, la acción colectiva es un término amplio que no habla solamente de protestas o rebeliones sino que se refiere a todas las ocasione en que un grupo de personas "confían y aplican recursos, incluyendo sus propios esfuerzos, para fines comunes” (Tilly y Tilly, 1981: 17). 
La organización se vuelve para $\mathrm{F}$ algo en la que encontrar una práctica social, cultural y comunicativa. F se percata que los que están en grupo son más fuertes, obtienen "más respeto" y más posibilidades de territorializar una determinada actividad, como el baile o el fútbol. También generan redes de protección paralelas a la organización, o redes delictivas no aprobadas por la organización pero que dependen de los lazos de amistad que en su interior aparecen. La organización permite una serie de dinámicas que permiten reconfigurar un pequeño mundo de posibilidades -la nación LK- al interior de otro mundo de prohibiciones -España-. "Como no voy a juntar a la gente si veo que no se logran poner de acuerdo, que no se reúnen, que no se reportan, que violan las reglas". El estar juntos implica restricciones y acuerdos reglamentarios, que a veces son imposiciones más que acuerdos, e implica sobretodo un sacrificio, es decir una enorme entrega a la nación, en medida no solo del trabajo y el tiempo que implica en términos organizativos, sino porque además es una opción frente a la pérdida de esperanza de ser visto como un ciudadano español.

En lugar de pensar que no "no se pertenece ya" al mundo que se deja (Ecuador-barriohogar), y "no se pertenece aún" al mundo que se llega (España-trabajo-inmigración) (Grinberg y Grinberg, 1984) podemos decir que F puede reconstruirse colectivamente en la medida en que no perteneció nunca al mundo que dejó y no va a pertenecer jamás al mundo al que llegó, es decir que estos dos mundos no son simplemente dos mundos distintos sino que son variaciones de una misma situación de exclusión que se repite y en la que $\mathrm{F}$ encuentra los elementos para construirse de modo antagónico.

El conflicto proveniente de Ecuador permite reanudar una conflictividad que les es negada en España. Es como si con los ciudadanos de segunda (o sea los no-ciudadanos) no se pudiera ni tener conflicto ya que este pasa por un reconocimiento mínimo. Se establece una situación de estigmatización cuando no policial. La conflictividad de la nación en Ecuador se transnacionaliza y permite que los grupos organicen una territorialidad propia de las dinámicas internas del grupo (capacidades organizativas, separaciones, disputa de liderazgo, saberes y estrategias de mantenimiento en el poder, etc.). Como lo muestra el testimonio previo, la confianza/desconfianza es entonces una de las lógicas dominantes de relacionamiento, visto que toda socialidad existe por fuera de la Ley.

Según Appadurai (1999), "la movilidad humana en el contexto de la crisis del Estadonación estimula el surgimiento de translocalidad". En este caso la translocalidad se refiere a que de la nación en Ecuador provienen los elementos para empoderarse en las condiciones de exclusión de la sociedad española. Se crea un puente entre los saberes de barrio de Ecuador y el proceso de territorialización en España que no pasa por las dimensiones ni simbólicas ni imaginarias del Estado-nación ecuatoriano o del Estadonación español. Se trata de una translocalización de una actitud-estrategia antagónica con respecto del entorno inmediato de rechazo, de la toma de conciencia de la paradójica realidad que viven los migrantes. 
Frente a la des-ciudadanización del emigrante la re-subjetivación en términos organizativos resulta una forma estratégica de supervivencia en términos culturales y sociales. Esto alimenta la paradoja ya expuesta por Appadurai en lo que concierne a vastas migraciones que viven procesos de despojo territorial e identitario, a lo que podemos sumar la explotación mediática y securitista en el caso de los jóvenes ecuatorianos en España. Appadurai afirma que:

Las concepciones modernas de ciudadanía, unidas a varias formas de universalismo democrático, tienden a exigir un pueblo homogéneo con paquetes estandarizados de derechos, pero las realidades del pensamiento etnoterritorial en las ideologías culturales del Estado-nación demandan que se discrimine entre diferentes categorías de ciudadanos, aun cuando todos vivan en el mismo territorio. El estatus civil (o el no estatus) de los palestinos con respecto al Estado de Israel es apenas el ejemplo extremo de esa contradicción. El acomodo de esos principios encontrados es cada vez más un proceso violento e incivilizado (Appadurai, 1999: 5).

No se puede decir que haya una conciencia organizativa como la de los movimientos sociales o políticos, $\mathrm{u}$ otros colectivos juveniles políticamente activos, sin embargo podemos dar cuenta de una serie de estrategias que permiten configurar un movimiento de visibilización de su propia práctica social y cultural. Se trata de una acción colectiva en su sentido más literal: un performance estratégico de sus colores y sus prácticas corporales en el espacio público español. Podríamos decir, agarrándonos de la poca ortodoxia académica y formalidad escritural de Michel De Certeau (1995) que se trata de una "táctica" organizativa, valga la pena el oximorón si así se lo quiere leer para recalcar el carácter precario de las aproximaciones al lenguaje y a las prácticas culturales a la vez juveniles y marginales. Al mismo tiempo, parte de la táctica de los Latin Kings es construir un lugar propio, una centralidad y una nación, aunque sea desde el margen. Esto la diferencia de otras organizaciones juveniles con sus tácticas sin centro.

La emergencia de este grupo juvenil tiene que ver en todos los casos con las translocalización de estrategias y tácticas de barrio de "tercer mundo" o de una periferia global, a espacios metropolitanos. Las relaciones de colonialidad o dominación en términos simbólicos se ven postergadas por estrategias de visibilización en un mercado global del consumo de imágenes que se muerde la cola. Es decir que se ponen a funcionar simultáneamente varias operaciones, por ejemplo en el año 2003: se abre el visado y sin embargo la inmigración a España crece (en su mayoría ecuatorianos) (Pajares, 2008); se criminaliza la inmigración más que nunca en la historia de la prensa española, se consagra el "milagro económico español" basado principalmente en el desarrollo del sector de la construcción en donde en los años 2006 y 2007 un 25\% de la mano de obra es extranjera (Pajares, 2008); se enmiendan tratados internacionales de migración como la Convención Internacional de Migraciones que ningún país de Europa desde 1991 lo ha 
ratificado, se empiezan a vender más discos de música latina y reguetón que inundarán los espacios españoles más que nunca. Estas operaciones, entre otras, muestran que las luchas se dan en diferentes territorios o registros culturales que tienden a confluir en la conflictividad social y que son capitalizados por lo jóvenes Latin Kings como formas, unas veces creativas otras violentas ${ }^{14}$, de "astucia" táctica.

\subsection{Salida (la vuelta). "Llegué a Quito como estaba sin maleta y sin nada, con 10 euros en el bolsillo"}

F había llegado a ser el "oficial de mayor rango" en Murcia, había podido juntar más de cien hermanitos y las actividades de la nación iban bien porque $\mathrm{F}$ había podido reorganizarla, reorientarla hacia actividades internas de provecho colectivo y sobre todo alejándola de cualquier forma de violencia. Su llegada a Murcia se debía a un asunto de corazón, tenía una relación de pareja con una de las hermanitas que ahí vivía. Su vida parecía finalmente haber encontrado un rumbo, un sentido, pensaba quedarse en España porque, en tan solo ocho meses, le habrían dado "los papeles" (la residencia) dado que ya tenía en España cuatro años y cuatro meses. En este momento se podía mantener aún con los ahorros acumulados gracias al trabajo de chofer de entrega a domicilio que tenía en Barcelona. Muchos hermanitos tenían su empleo y llevaban una vida tranquila entre el trabajo y las actividades de la nación. F logró reconstituir las reuniones universales, aunque estas debían realizarse en lugares poco frecuentados, oscuros: "nos reuníamos en un bosque y cada uno llegaba por su lado no en un grupo". La cautela era de rigor dado que la policía estaba al acecho buscando el momento propicio para intervenir, para desmantelar las "bandas latinas".

En la reunión para planificar el festejo del día de San Valentín (en el que se hace intercambio de regalos entre todos), se juntan en casa de King $\mathrm{C}$ unos quince hermanitos entre los que esta F, cuando llega la policía, la cual evidentemente estaba detrás de él. F intenta darse a la fuga porque sabía que lo buscaban: los padres de la chica con la que tenía una relación lo habían denunciado a la policía cuando su hija se fue a vivir con él y porque su condición de "sin papeles" lo hace vulnerable (ya había sido registrado como "ilegal” en otra detención en Barcelona). La casa está rodeada de agentes, tienen linternas e impiden que F se escape. La escena se desarrolla muy rápido, F logra esconder su collar y las hojas de la "literatura" que tiene, aquella literatura que le ha permitido establecer un liderazgo en España. El jefe del grupo policial le notifica que su expulsión es un hecho y que tiene que ejecutarse inmediatamente. F le objeta (se lo había dicho su abogada que estaba tramitando la apelación a la primera detención) que tiene dos meses para intentar resolver su situación legal. El otro le dice que no, que ya tiene que irse, ipso

14. La caracterización de esta acción colectiva tendría desbordes que ameritarían ser tratados en el marco también de las condiciones de reproducción de la marginalidad en situación de migración, como lo son las prácticas de violencia o agresividad. 
facto, que es un deportado.

Me bajaron a investigaciones y estuve encerrado 2 días en el calabozo. Luego a Madrid, ahí encerrado unas horas (en celdas con marroquíes y un poco de gente...) y al avión esposado. El policía joven me decía que no sabía por qué me expulsaban, si hay manes peores que vos. Yo le decía además que la $\mathrm{E}$ estaba embarazada.

Me pedían que firme un papel de expulsión y yo no quería firmar hasta que llegara un abogado, me faltaban solo ocho meses para que el gobierno español me de los papeles, quiera o no... (ya iba 4 años 4 meses, era el 11 de febrero de 2006).

Me llevaban en un patrullero escoltado, esposado como si fuera un delincuente de alto riesgo. ¿Los manes qué pensarían?

Cuando despegó el avión se me fueron las lágrimas, seguía esposado. En Colombia me esperaba la policía colombiana para meterme también en la celda.

Ya llegando a Quito mi hermano me hizo escuchar la canción de Ricardo Arjona, el vencedor, el viajero, o algo así.

Yo, lo único que quería era hablar con E. Ella y los otros pensaban que estaba en los calabozos de la policía de Murcia, porque eso les habían dicho los policías. Algunos días después supe que $\mathrm{E}$ abortó obligada por sus padres.

Ese aborto guardaba una relación muy significativa con la frustración que F experimentaba en los primeros días en Quito, casi una metáfora del fracaso que finalmente había sido su estadía en España. Y la nación, nuevamente lo esperaba para tenerlo en sus entrañas, calientes y frías a la vez, en una suerte de fatalismo sin nombre y sin fin.

F ha vuelto a ser uno de los líderes de la nación en tierras ecuatorianas. Actualmente se desempeña como el representante de la constituida Corporación de reyes latinos y reinas latinas del Ecuador y su labor va dirigida a consolidar el proceso de transformación. A ratos me confiesa que extraña mucho España, su vida ahí, que a pesar de las penurias por las que paso le dio la posibilidad de crecer mucho. Incluso no les faltan las ganas de querer regresar especialmente cuando las cosas de la nación no salen como él quisiera. No podrá hacerlo . 


\section{REFERENCIAS BIBLIOGRÁFICAS}

Appadurai, Arjun (1999) "Soberanía sin territorialidad. Notas para una geografía posnacional”. Nueva Sociedad 163, pp. 109-125.

Auge, Mark (2000) Los no lugares, espacios del anonimato. Barcelona: Gedisa.

Bhabha, Homi (2002) El lugar de la cultura. Buenos Aires: Manantinal.

Botello, Santiago y Ángel, Moya (2005) Reyes Latinos. Los códigos secretos de los Latin Kings en España. Madrid: Ed. En Primera Persona.

Brotherton, David y Barrios, Luis (2004) The Almighty Latin King and Queen Nation, Street politics and the transformation of a New York City gang. New York: Columbia University Press.

Cerbino, Mauro (2006) Jóvenes en la Calle, cultura y conflicto. Barcelona: Anthropos.

Chambers, Iain (1994) Migración, cultura, identidad. Buenos Aires: Amorrortu.

De Certeau, Michel (1995) La invención de lo cotidiano 1. Artes de hacer. México: Universidad Iberoamericana.

Deleuze, Gilles y Guattari, Felix (1991) Qu'est-ce que la philosophie?. Paris: Les Editions de Minuit.

Delgado, Manuel (2007) Sociedades Movedizas: pasos hacia una antropología de las calles. Barcelona: Anagrama.

Delpino, María Antonieta (2007) La inserción de los adolecentes latinoamericanos en España. Algunas claves. Madrid: Observatorio de la Infancia No 4, Ministerio de Trabajo y Asuntos Sociales.

Fanon, Fanon (1968) Piel Negra Máscaras Blancas. La Habana: Instituto del Libro.

Feixa, C. ; Porio, L. y Recio, C. (eds) (2006) Jóvenes Latinos en Barcelona. Barcelona: Anthropos.

Gilroy, Paul (1993) The black Atlantic: modernity and double consciousness. Cambridge, Mass: Harvard University Press.

Grinberg, León y Grinberg, Rebeca (1984) Psicoanálisis de la migración y del exilio. Madrid: Alianza Editorial. 
Hall, Stuart (1997) Representation. Cultural representation and signifying practices. London: Open University, Sage Publications.

Gioconda Herrera y Ramírez Jacques (Eds.) (2008) América Latina migrante: Estado, familia, identidades. Quito: FLACSO Ecuador.

Kim, Tia (2004) Youth gangs. Riverside: Southern California Center of Excellence on Youth Violence Prevention. Berkley: University of California.

Marcus, George (2001) "Etnografía en/del sistema mundo. El surgimiento de la etnografía multilocal”. Revista Alteridades 22, pp. 111-127.

Martín, E.; Benítez, J.; Castellani, S. y Cuberos, F. (2012) Vidas de “iday vuelta". Inmigrantes latinoamericanos en Sevilla. Sevilla: Universidad de Sevilla.

Martín, E.; Cuberos, F. y Castellani, S. (2012) "Latin American Immigration to Spain: discourses and practices from 'la madre patria"'. Cultural Studies, (i-first).

Pajares, Miguel (2008) Informe del mercado laboral en España, Documento no. 17 del Observatorio permanente de la inmigración, Ministerio de trabajo e Inmigración de España. http://www.tt.mtin.es/periodico/inmigracion/200807/merc_Trabajo_ Inform_08.pdf [consultado el 15 de noviembre de 2011].

Pedone, Claudia "La inmigración extracomunitaria y los medios de comunicación: la inmigración ecuatoriana en la prensa española", Scripta Nova, Revista Electrónica de Geografía y Ciencias Sociales, no 94 (43) http://www.ub.es/geocrit/sn-94-43.htm [consultado el 10 de octubre de 2011].

Queirolo, Luca (ed.) (2009) Dentro le gang, giovani, migranti e nuovi spazi pubblici. Verona: Ombre Corte.

Queirolo, L.; Cannarella, M. y Lagomarsino, F. (2007) (a cura de) Hermanitos, Vita e política della strada tra i giovani latinos in Italia. Verona: Ombre Corte.

Suárez-Orozco, Carola (2000) "Identities under siege. Immigration stress and social mirroring among the children of immigrants". En: Robben, A. y M. Suárez-Orozco (eds.). Cultures under siege. Social violence \& trauma. Nueva York: Cambridge University Press.

Tilly, Louise A. y Tilly, Charles (1981) Class, Conflict and Collective Action. Londres, Sage Publications.

Stolcke, Verena (1995) "Nueva retórica del exclusión en Europa" http://www.cholonautas. edu.pe/modulo/upload/NUEVA\%2ORETORICA\%20DE\%20LA\%20EXCLUSION-STOLCKE.pdf [Consultado el 20 de enero de 2009]. 


\section{ARTÍCULOS DE PERIÓDICOS:}

Diario El País, escrito por David Reher y Blanca Sánchez Alonso, profesores investigadores. Disponible en: http://www.elpais.com/articulo/opinion/excepcionalidad/ espanola/elpepuopi/20090218elpepiopi 13/Tes. 